\title{
NOVAMENTE SOBRE A TRADUÇÃO: UMA RESPOSTA A LU XUN
}

Qu Qiubai

Tradução de Li Ye 1 1Pesquisadora independente, Florianópolis, Santa Catarina, Brasil

Caro camarada,

Por estar doente, demorei em te responder. Por favor me perdoe.

Tradução ainda é uma questão extremamente importante na China. Desde o "Movimento de Quatro de Maio", essa questão foi levantada muitas vezes e várias vezes foi tema de controvérsia. Mesmo assim, a discussão sobre os princípios básicos da questão ainda não foi resolvida. Na verdade, há duas causas para as discussões do ano passado: uma é o princípio que afirma que "deve-se evitar a tradução não fluente mesmo que isso implique alguma inexatidão", apresentado pelo Sr. Zhao Jingshen, e a outra é o princípio levantado por mim mesmo que afirma que "deve-se adotar, sem sombra de dúvida, o chinês vernáculo para traduzir corretamente algumas coisas". Sr. Zhao e eu somos diametralmente opostos. "Mesmo que isso implique alguma inexatidão"! Que tipo de afirmação é essa? É realmente um absurdo. Por isso não temos a necessidade de discutir com ele. Porém, em resposta ao Sr. Zhao, Notícias de Literatura (Wen Yi Xin Wen) uma vez afirmou que "deve-se alcançar a exatidão mesmo que isso implique uma tradução não fluente". A meu ver, essa forma de tradução também não tocou na essência da questão e ficou praticamente no nível da afirmação do Sr. Zhao. Por causa 
disso eu levantei esse assunto na última carta. Na sua carta você também afirmou que: "até hoje eu defendo 'fidelidade mesmo à custa de fluência'”. Eu acho que isso é uma forma errada de propor a questão. O que está em questão não é a "fluência", mas "se a tradução pode contribuir para o desenvolvimento da língua chinesa moderna". Em primeiro lugar, se realmente fosse adotada a língua chinesa moderna (chinês vernáculo usado oralmente por chineses) para realizar a tradução, não teria a discussão sobre tradução não fluente e nem seria levantada a questão de fluência. Segundo, se a língua usada não é a língua chinesa moderna, mas o "latim do Extremo Oriente" (chinês clássico) ou o chinês semi-clássico com estilo das pessoas empregadas por estrangeiros (como na tradução do Sr. Zhao), então a tradução, mesmo que seja fluente como o estilo clássico da tradução de Yan Fu, não tem nada a ver com os 300 milhões de chineses vivendo na China hoje em dia. Isso também se aplica à questão de "fidelidade".

That is the question. Aqui é onde o problema está.

O que você falou, "fidelidade mesmo à custa de fluência" ou "no momento podemos tolerar um certo grau de não fluência", é não prestar muita atenção ao princípio de que o chinês vernáculo deve ser adotado como o padrão absoluto.

Como eu já falei na última carta: “[o] verdadeiro chinês vernáculo refere-se à língua chinesa moderna que é realmente fluente. É claro que o chinês vernáculo referido aqui não se limita ao chinês vernáculo usado nas "tarefas domésticas", quer dizer, o chinês vernáculo abrange desde a conversação ordinária de pessoas comuns à linguagem usada por professores universitários nas suas palestras... Palavras escritas em papeis (a língua escrita) devem ser como esses tipos de língua, somente com uma organização relativamente mais compactada e ordenada."

O chinês vernáculo absoluto como definido aqui deve ser adotado para a tradução: por um lado a tradução terá sentido exatamente igual ao do texto original ("fidelidade") e, por outro lado, essas frases e palavras da tradução poderão ser faladas pelas bocas dos chineses ("fluência"). "Fidelidade" e "fluência" não devem ser 
vistos como termos antagônicos. Não devemos falar " 'fluência' à custa de 'fidelidade"”, "fidelidade' à custa de 'fluência"”, ou "um certo grau de não 'fidelidade' deve ser tolerado para alcançar a 'fluência'" e "um certo grau de não 'fluência' deve ser tolerado para alcançar a "fidelidade"”.

O erro fundamental do Sr. Zhao Jingshen é considerar as palavras "fidelidade" e "fluência" como contraditórias.

Como o exemplo que você mencionou na sua carta: "Shan Beihou, taiyang luoxiaqule" (atrás da montanha, o sol desceu). Você acha que essa frase é um pouco "não fluente", mas na verdade isso é chinês vernáculo muito fluente. Somente o Sr. Zhao iria falar que isso é "não fluente". Caso essa frase seja mudada para "Ri luo Shanyin" (o principal corpo celeste do sistema solar desceu pelo lado oeste da montanha), seria realmente não fluente, porque não há possibilidade que as pessoas comuns, que não são como o Sr. Zhao, entendam uma frase assim. Há vocábulos, tais como "ri" e "yin", na linguagem oral das pessoas comuns? Não. No dicionário da língua chinesa dos chineses vivos não há palavra como "ri"; em vez disso há somente "taiyang" ou "ritou" (a palavra "ri" em "zhengyue chuyi ri" < o dia primeiro do primeiro mês do ano novo chinês $>$ tem sentido diferente).

Caso "não fluente" tenha apenas o sentido de "novo e fresco", ou seja, "[algo que] não é visto comumente e nem é ouvido comumente", não há nenhum problema nisso. Quando traduzimos ou até escrevemos nossos próprios textos, claro que devemos usar, corajosamente, novos meios de expressão, novas palavras e novas estruturas de frases. Mas tornar a afirmação "fidelidade à custa de fluência" em um princípio, enfim, é muito inadequado. Primeiro, devemos fazer com que as novas palavras, as novas estruturas de frases, como outras coisas que inventamos, possam ser faladas oralmente e ter condição de "fluência", pois, caso contrário, esses novos métodos de expressão serão abortivos. Segundo, não devemos nos permitir um caminho mais fácil e aceitar tudo que é "não fluente". Essa tendência pode causar resultados muito prejudicais: tradutores jovens não darão atenção à necessidade das massas e 
consequentemente eles criarão novas "palavras" (tal como ocorreu com "niuxian" < literalmente quer dizer torcer e aparecer > e "yiweizhe" < significar, implicar >) através da combinação de caracteres tirados do Dicionário de Kangxi. Esses tradutores criam muitas frases confusas e vagas utilizando palavras funcionais abreviadas seguindo os diagramas de análise de sintaxe inglesa.

O problema mais importante aqui é: para criar novos métodos de expressão é preciso satisfazer a condição de "poder ser falado" oralmente. Isso quer dizer, algumas palavras e estruturas de sentença novas, apesar de não existirem originalmente em língua chinesa e não serem muito familiares para as massas no início, têm a potencialidade de ser assimiladas gradualmente pela linguagem das massas, visto que elas podem ser faladas oralmente. Caso tenhamos a intenção de aceitar traduções "não fluentes", nós privamos essa potencialidade, fazendo com que esses novos métodos de expressão não possam se transformar de linguagem escrita para linguagem oral. Consequentemente, isso, de uma forma indireta, mantém o sistema de chinês escrito e a influência do chinês clássico e mata os novos métodos de expressão.

A sua carta mencionou as palavras novas que enumerei, incluindo "bagong (greve)". Você compreendeu totalmente o que quero dizer: eu não sou contra os novos métodos de expressão; em vez disso, eu exijo que esse novos métodos de expressão possam ser assimilados às vidas das massas. Escrevi na minha última carta:

Em geral, hoje em dia quase todos os literatos, filósofos, comentaristas políticos... não só na tradução, mas também ao escreverem suas próprias obras, para poderem apresentar as novas relações, novos fenômenos, novas coisas e novos conceitos que já existem na presente sociedade da China, têm que ser um "Cang Jie" ${ }^{1}$. Isso quer dizer, têm que criar novas palavras e novas estruturas de frase todos os dias... Mas, a invenção dessas novas palavras e novas estruturas de frase... deve seguir as regras gramaticais do chinês vernáculo.

${ }^{1} \mathrm{Na}$ crença popular chinesa, o lendário Cang Jie é o inventor dos caracteres chineses. 
Por isso essa questão é bem clara. Tanto você quanto eu advogamos a introdução de novos métodos de expressão, mas eu advogo a rejeição completa da atitude de "tolerar um certo grau de não fluência".

Na sua carta você falou que: “A gramática da língua chinesa, tanto escrita quanto oral, é muito imprecisa... A tradução deve disseminar, não só novos conteúdos, mas também novos métodos de expressão." Introduzir novos métodos de expressão claro que não é um problema. O problema é distinguir rigorosamente a língua chinesa escrita da língua chinesa oral. Na verdade, o chinês clássico é diferente do chinês vernáculo como o latim é diferente do francês. Devemos reconhecer isso em primeiro lugar. O chinês clássico é a língua nacional dos "estudiosos oficiais" e não tem nada a ver com o povo comum. Se o chinês clássico necessita da introdução de novos métodos de expressão ou não é outra questão e é questão dos mestres veneráveis, não nossa. Em relação à língua chinesa moderna (isto é, chinês vernáculo), eu já escrevi na minha última carta:

Tradução - além de introduzir novos conteúdos aos leitores chineses - tem mais uma função importante: que é nos ajudar a criar uma nova língua chinesa moderna. A língua chinesa (incluindo a língua escrita) é tão deficiente que até lhe faltam nomes para muitos objetos de uso cotidiano. De fato, a língua chinesa não está totalmente desenvolvida e fora do nível de uma "linguagem de sinais" - a conversa cotidiana e comum ainda quase depende dos "gestos". Claro, há quase uma ausência completa de adjetivos, verbos e preposições que expressem diferenças sutis e relações complicadas. Os vestígios do feudalismo patriarcal da Idade Média continuam acorrentando a língua viva dos chineses (não só das massas dos trabalhadores industriais e rurais). Nessa situação, a criação de uma nova língua é uma tarefa muito importante.

Isso é o que você falou: "A língua chinesa... é muito imprecisa"... "Quando falamos, muitas vezes as palavras não conseguem transmitir o que queremos expressar. Em outras palavras, a nossa língua é deficiente. É por isso que os professores têm que escrever com giz para os ajudar a explicar coisas.” Por isso, você e eu 
temos que advogar "a introdução de novos métodos de expressão através da tradução". Mas você apenas falou: "Para tratar esta doença, eu acho que temos que continuar fazendo numa forma difícil, incorporando estruturas de frase estranhas, antigas, dialectais e estrangeiras até que um dia isso se tornará uma parte própria da nossa língua." Isso não é suficiente. Além de adotar estruturas de frase estranhas, temos que considerar como essas estruturas podem se tornar "uma parte própria da nossa língua". Caso na tradução só nos concentremos em "incorporar estruturas de frase estranhas" e não consideremos se essas estruturas possam ser faladas por pessoas vivas, essas "estruturas estranhas nunca poderão se tornar uma parte própria da nossa língua”. Nesse caso, os novos métodos de expressão serão sempre métodos de expressão "escritos com giz no quadro negro"! Devemos adotar uma nova diretriz: esforçarnos muito para que as novas palavras e as novas estruturas de frase se tornem vivas e todos esses novos métodos sejam assimilados à língua viva. Não devemos ter intenção prévia de esperar pela eliminação natural (de palavras e estruturas de frase estranhas). Certamente, entre essas novas palavras e estruturas de frase, muitas provavelmente ainda serão eliminadas. Mas caso todos os tradutores esperem, com intenção prévia, pela eliminação natural, em vez de se responsabilizem o máximo possível em tornar as novas palavras e estruturas de frase que escreveram em novos métodos orais de expressão, essas atividades de tradução não poderão ajudar o desenvolvimento da língua chinesa moderna.

Hoje em dia, não só a tradução, mas também a literatura e a arte ocidentalizada e o tal chamado "chinês vernáculo escrito" são afetados por essa doença. Essas atitudes irresponsáveis, além de não poderem contribuir para o desenvolvimento do chinês vernáculo, também causaram uma linguagem que não é nem peixe nem carne, ou seja, um novo chinês clássico que é meio vernáculo meio clássico. Há inúmeros exemplos reais assim. [...]

Isso é Lin Shuísmo do "Movimento de Quatro de Maio" e este novo Lin Shuísmo está bem na moda no presente. Jin Ding consegue escrever chinês vernáculo verdadeiro, mas escolheu escrever 
com rodeios. Isto é especialmente um pecado imperdoável. Chamei de "pecado", o que absolutamente não é exagero. Lembro-me que li em uma revista onde alguém condenou o uso do provérbio "jietu mieguo" (uma conspiração de dividir dois países vizinhos, a fim de conquistá-los um após o outro) no título de um jornal para as massas e considerou isso como "um pecado contra a revolução".

Isso não é introduzir novos métodos de expressão, mas é estragar os novos métodos de expressão.

Para introduzir novos métodos de expressão, claro que temos que fazê-lo "numa forma difícil”. Essa sua afirmação é correta. É natural que os "novos" métodos sejam menos familiares no início. Eles fazem as pessoas pensar. Pessoas como Sr. Zhao Jingshen querem traduzir textos estrangeiros com os clichês (o chamado "fluente") familiares para os literatos. Além disso, eles traduzem de forma errada deliberadamente. Claro que isso é muito estúpido. Com essa atitude preguiçosa, acontece uma tendência de pensamento confuso de "se contentar com uma compreensão superficial”. Sr. Zhao Jingshen até declarou em publico sem vergonha que "se deve evitar a tradução não fluente mesmo que isso implique alguma inexatidão". Isso é como escrever um epitáfio no estilo da Escola de Tongcheng, desde que o texto "corresponda com o estilo", pode-se inventar histórias sobre fidelidade, piedade filial, integridade e justiça, de modo indiferente da situação real do falecido. Isto é outro aspecto do Lin Shuísmo.

Agora para iniciar uma nova revolução literária, uma luta por uma nova língua escrita, devemos derrubar o novo Lin Shuísmo. E isso significa o reconhecimento firme e claro do princípio de estabelecer o chinês vernáculo como padrão.

A língua nova deve ser a língua das massas - a língua que as massas conseguem entender e utilizar. Como a língua chinesa não é precisa, devemos torná-la mais precisa. Como a língua chinesa não é clara, devemos torná-la mais clara. Como a língua chinesa não é rica, devemos torná-la mais rica. Quando realizamos a tradução, o objetivo de introduzir novos métodos de expressão é tornar a língua chinesa moderna mais precisa, clara e rica. Podemos usar 
algumas fontes do chinês clássico: como as raízes dos caracteres, os provérbios e as palavras de função, com a condição de que essas raízes, provérbios e palavras de função possam se tornar uma parte do chinês vernáculo e ser falados oralmente, além de aumentar o nível da precisão, clareza e riqueza do chinês vernáculo. Caso esse objetivo não possa ser alcançado, não faz sentido falar sobre novos métodos de expressão. Devemos adotar a mesma atitude quando usamos palavras e estruturas de frase dos textos estrangeiros.

Isto é a forma que pode realmente enriquecer a língua chinesa (incluindo a língua escrita).

Claro, no início da introdução dos novos métodos de expressão, é preciso "fazê-lo de uma forma difícil", ou seja, pensar um pouco a mais, ponderar um pouco a mais. Porém essas ponderações deveriam ser úteis fazendo com que os novos métodos de expressão possam ser realmente assimilados no chinês vernáculo moderno, em vez de sempre "depender de giz".

Além disso, você levantou uma nova questão, dividindo os leitores em duas categorias: "Categoria A, leitores com nível alto de educação; Categoria B, leitores com nível básico de alfabetização" e acha que "é necessário dividir leitores em níveis diferentes e realizar traduções em versões diferentes correspondendo com os níveis dos leitores". Eu acho que não podemos fazer (a tradução) dessa forma. Escrever o seu próprio texto é uma coisa e fazer tradução é outra. Quando escrevemos e elaboramos por nós próprios, é claro que temos que distinguir os níveis dos leitores e agora os mais necessários são os livros mais fáceis de entender. Quando precisamos usar materiais estrangeiros, os autores chineses devem assumir responsabilidades maiores de "adaptação". Quanto à tradução, já que é traduzir, deve ser em conformidade total com o texto original. Os tradutores não têm liberdade de alterar o nível das obras originais.

O que é preciso agora é uma grande quantidade de todos os tipos de livros populares, que explicam aos poucos os novos substantivos de ciência e de arte com o chinês vernáculo moderno e popular e que introduzem gradualmente muitas novas palavras e estruturas de frase. Assim construímos uma escada necessária, com que os 
leitores comuns podem chegar a um nível mais alto e entender a tradução das obras de ciência e de arte do mundo.

Na França há um ditado: "La mort saisit la vie" - A morte captura a vida. As massas da China não têm a possibilidade de receber uma educação de nível alto. O sofrimento deles com a confusão causada pelo chinês clássico refletiu justamente esse provérbio. As forças residuais do feudalismo acorrentam-nos em todos os aspectos. A exploração dos burgueses até causou a monopolização dos conhecimentos. Além disso, soldados na frente da guerra cultural como Sr. Zhao Jingshen deliberadamente fazem com que as massas leiam traduções erradas. E as políticas prejudiciais como "mulas revolucionárias" - escrevem artigos sobre a revolução com o novo chinês clássico que é meio chinês clássico e meio chinês vernáculo. Tudo isso é a força da morte. Devemos mobilizar todas as forças para derrubar esses zumbis.

No final quero falar sobre a tradução de Yan Fu e a tradução das escrituras sagradas do budismo. A tradução das escrituras sagradas do budismo realmente trouxe muitas contribuições para a história cultural da China. Primeiro, a tradução das escrituras sagradas do budismo foi a primeira vez em que a China usou a sua própria "língua mais simples" para traduzir a língua mais complicada da família das línguas indo-germânicas - o sânscrito. Segundo, a tradução das escrituras sagradas do budismo na realidade iniciou o uso do chinês vernáculo - as citações de Song Ru na verdade estavam imitando as escrituras sagradas do budismo. Além disso, de acordo com os materiais existentes, as primeiras literaturas em chinês vernáculo foram criadas sob a influência das escrituras sagradas do budismo. A literatura popular das cinco Dinastias (Dinastias Liang, Tang, Jin, Han e Zhou) nas grutas de Dun Huang são registros das pregações das escrituras sagradas do budismo. A evolução da tradução das escrituras sagradas do budismo da Dinastia Han à Dinastia Tang também é a evolução do chinês clássico ao chinês vernáculo. Claro, o chamado chinês vernáculo aqui é apenas uma mistura de chinês clássico como padrão de linguagem com um pouco de chinês vernáculo. 
A evolução da tradução de Yan Fu ocorreu, na verdade, da mesma forma. Da sua tradução de "Evolução e Ética" à tradução de "A Riqueza das Nações", para ser fiel ao texto original, foi inevitável a criação de novos estilos através do uso do chinês vernáculo. Mas na tradução dele, igual como na tradução das escrituras sagradas do budismo, o uso do estilo similar ao do chinês vernáculo ocorre pela obrigação do conteúdo do texto original. E a tradução dele sempre usa o chinês clássico como padrão. Esse chinês clássico usado na tradução, depois de algumas mudanças graduais, criou o posterior "ensaio de oito partes", a mesma linguagem utilizada na tradução do "Relatório do Juiz Feetham", ou seja, um chinês clássico usado atualmente em todos os tratados, artigos das leis e livros didáticos de ciência dos ortodoxos. Por isso, em perspectiva histórica, Yan Fu realmente pode ser considerado um dos últimos literatos da Idade Média da China. Os textos das pessoas como Yan Fu, Lin Qinnan e Liang Qichao merecem ser exibidos no Museu de História. Eles são espécimes que podem mostrar para as gerações futuras como os últimos estudiosos oficiais da Idade Média da China eram pobres e como eles foram obrigados pelas novas forças da sociedade a abandonarem a sua posição passo a passo, afastando-se do domínio do chinês clássico da Idade Média, mas ao mesmo tempo tentando criar uma nova dominação pelo chinês clássico seguindo firmemente os resquícios do chinês clássico. Mas essa dominação está finalmente falindo. Ocorreu um grande motim durante a época de "Quatro de Maio" que estremeceu a base dessa dominação. Ultimamente, um novo motim começou com o objetivo de retirar completamente esse problema da Idade Média.

Na nova China, abaixo do Instituto de Ciência será estabelecido o Departamento de Língua Chinesa Antiga (equivalente a Departamento de Língua Sânscrita Antiga, Língua Grega e Língua Latina). Os mestrandos desse departamento devem ter que analisar as traduções das pessoas como Yan Fu, porque a chamada Língua Chinesa Antiga inclui a língua chinesa de "Shi Jing" (O Clássico da Poesia) e de "Shu Jing" (O Clássico de Documentos) à língua chinesa de 
"Da Tongshu" (Livro de Grande Harmonia) de Kang Youwei (claro, a chamada Idade Antiga também é dividida em várias épocas).

Devemos aceitar todos os patrimônios culturais da Idade Antiga e das classes dominantes, julgar e criticar os seus valores. Essas coisas, essas antiguidades servem apenas como materiais para a nossa pesquisa. Para as massas, essas coisas têm muito pouco valor e somente valor de referência. As obras científicas, como "Evolução e Ética”, que realmente têm valor devem ser retraduzidas em língua chinesa moderna.

E você falou que a diferença entre Mestre Yan Fu e Sr. Zhao Jingshen é como "a diferença entre tigre e cachorro", eu acho isso muito correto. Sr. Zhao Jingshen é como a poeira dos resquícios feudais e não vale a pena ser exibido no Museu Histórico. O Zoológico de Beijing precisa de tigres, porque tigre é raro; mas o zoológico não necessita de cachorros, porque cachorro há em todos os lugares. Caso o museu exiba as traduções que cometeram erros de tradução com intenção, será realmente um desperdício de espaço!

Escrevendo sem pensar muito, eu não esperava ter escrito tanto, por enquanto vou dar uma "paradinha".

20 de junho de 1932

Da “Antologia de Qu Qiubai”

Recebido em: $15 / 08 / 2020$

Aceito em: 05/12/2020

Publicado em janeiro de 2021

Li Ye. E-mail: lidia20060524@hotmail.com. ORCID: https://orcid.org/00000003-0401-5691. 
